\title{
Antitransitive Relationship
}

National Cancer Institute

\section{Source}

National Cancer Institute. Antitransitive Relationship. NCI Thesaurus. Code C75922.

A binary relation such that an element $a$ is related to an element $b$, and $b$ is in turn related to an element $\mathrm{c}$, but $\mathrm{a}$ is not related to $\mathrm{c}$. 